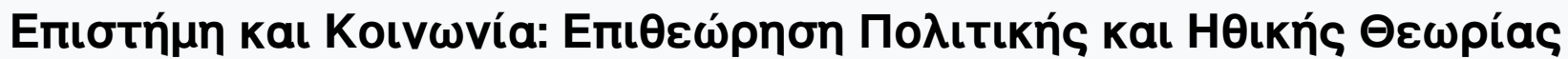

Tóp. 5 (2001)

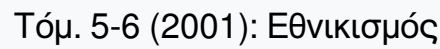

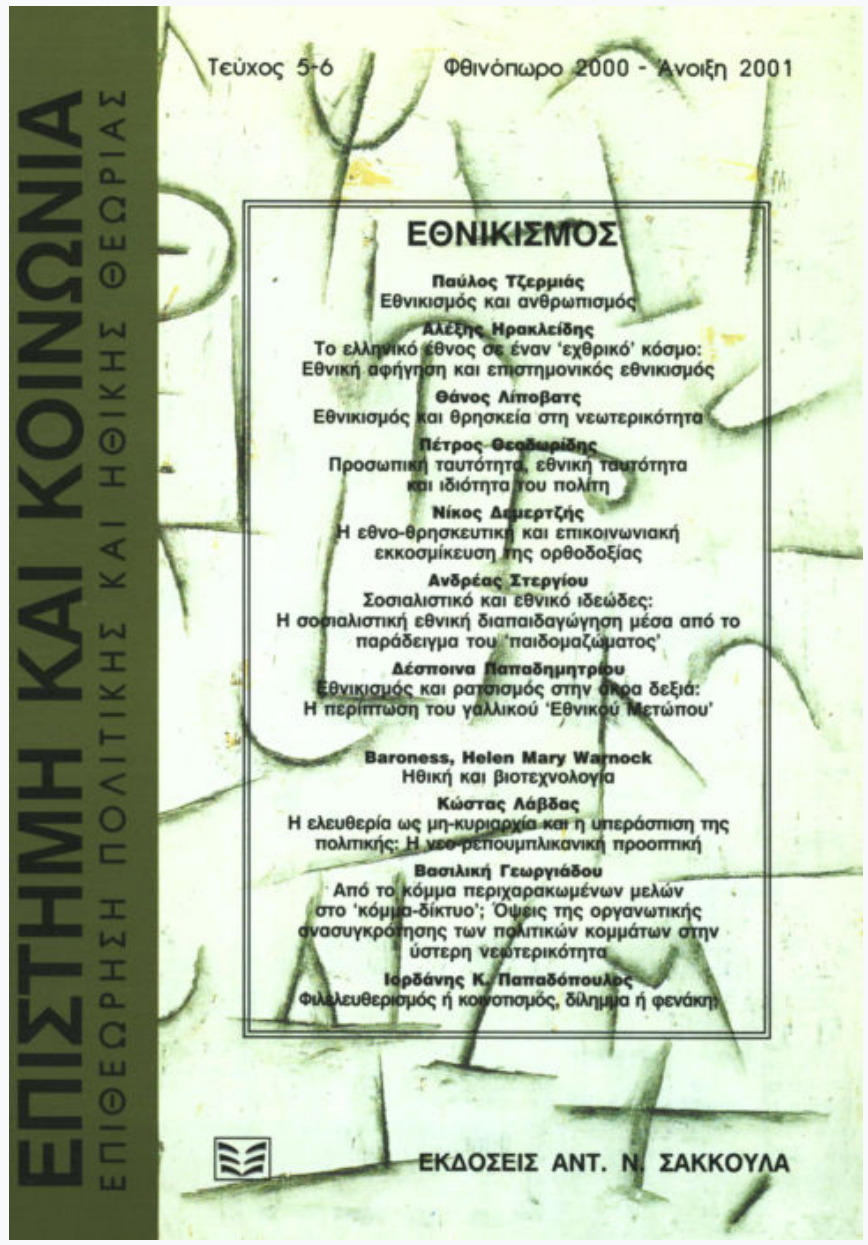

Lawrence R., Jones-Fred Thompson, Public Management: Institutional Renewal for the twenty-

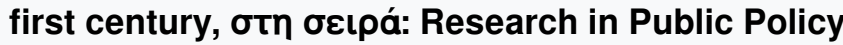
Analysis and management, Vol.10

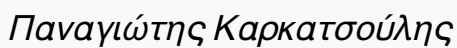

doi: $\underline{10.12681 / \text { sas. } 556}$

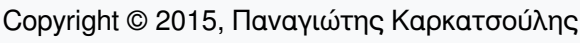

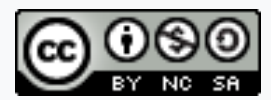

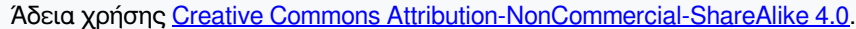

\section{Bıß入ıорачıкń avaчopá:}

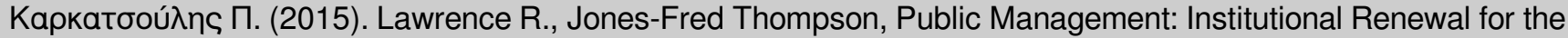

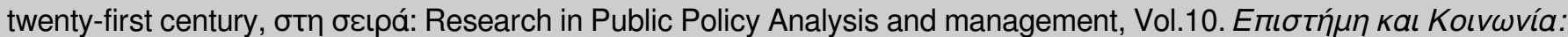

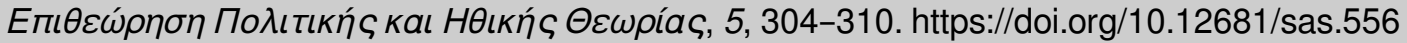


Lawrence R., Jones-Fred Thompson, Public Management: Institutional

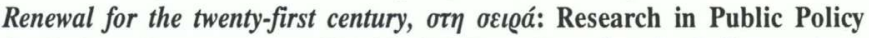
Analysis and management, Vol.10, (Jai Press Inc., Stamford, Connecticut,

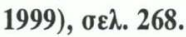

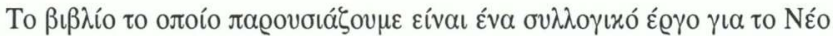

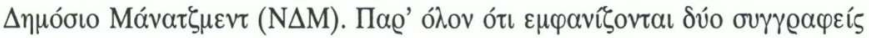

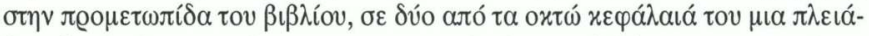

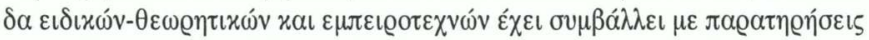

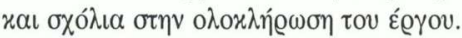

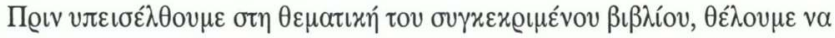

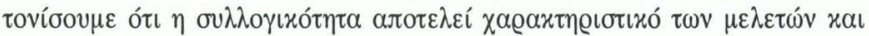

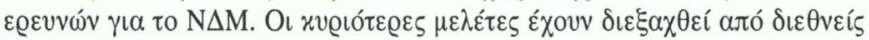

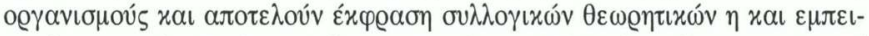

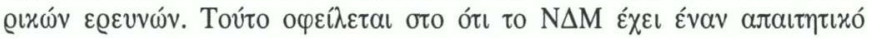

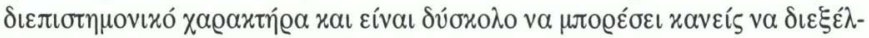
$\theta \varepsilon \iota$ a

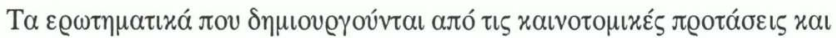

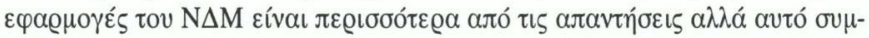

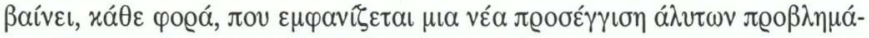

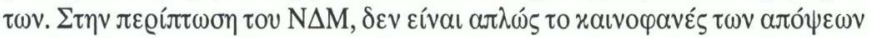

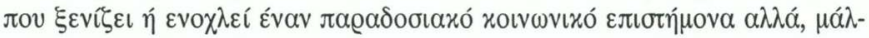

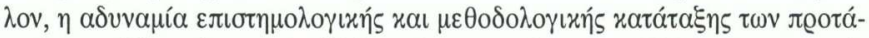

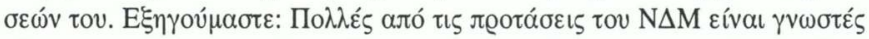

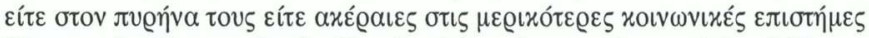

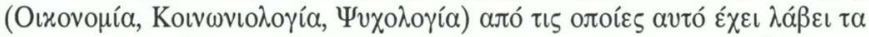

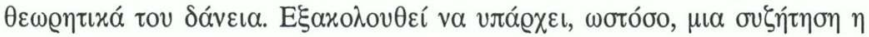

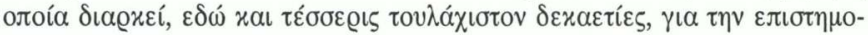

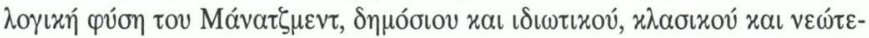

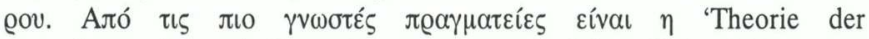

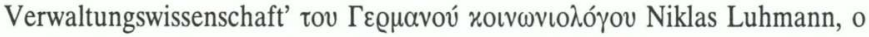

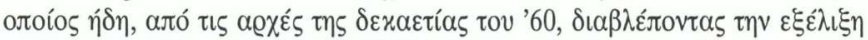

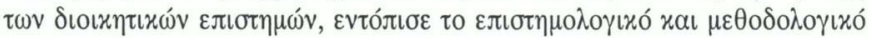

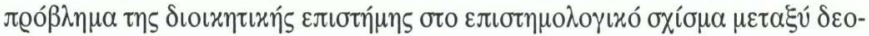

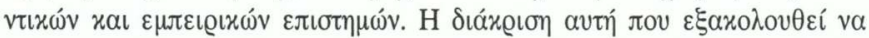

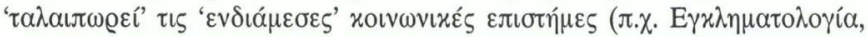

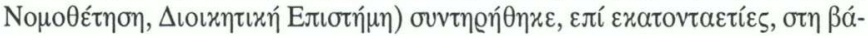




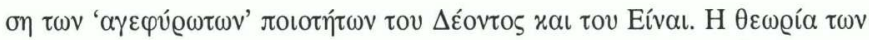

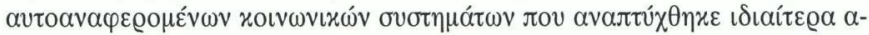

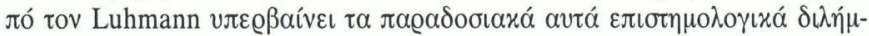

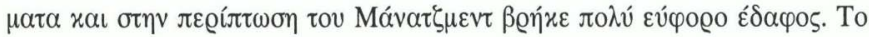

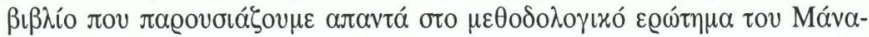

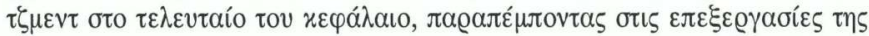

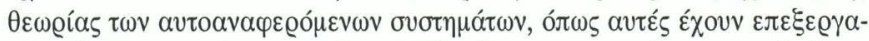

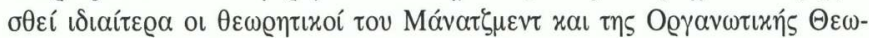

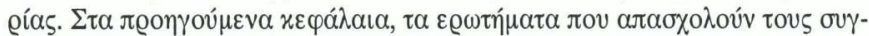

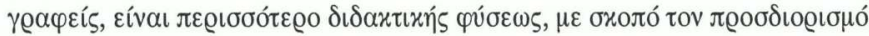

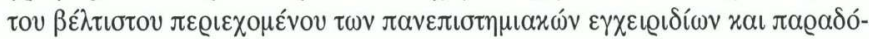
$\sigma \varepsilon \omega v$.

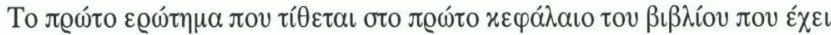

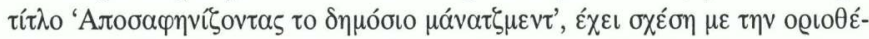

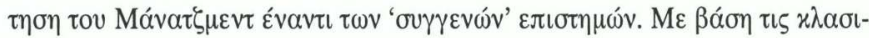

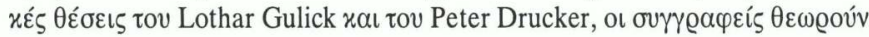

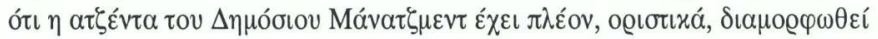

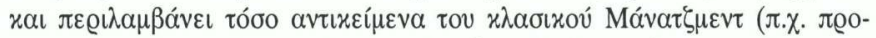

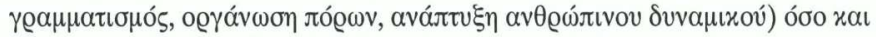

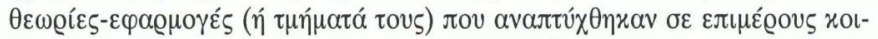

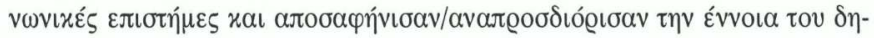

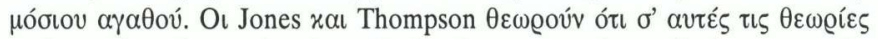

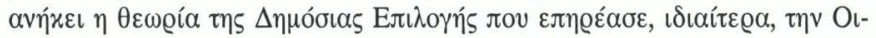

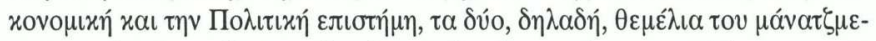

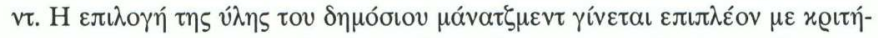

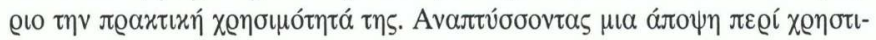

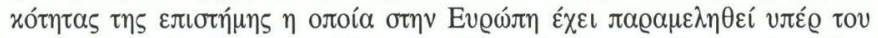

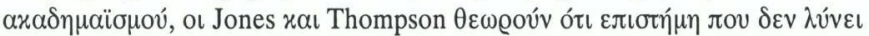

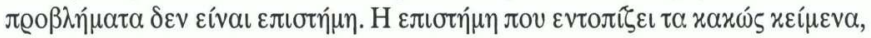

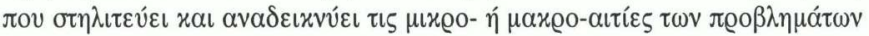

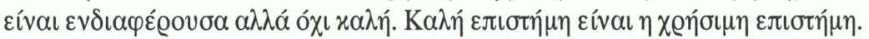

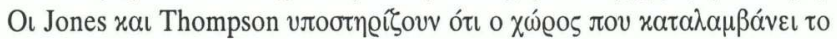

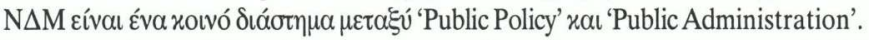

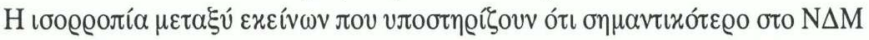

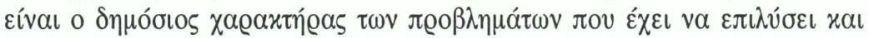

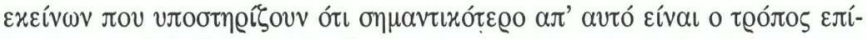

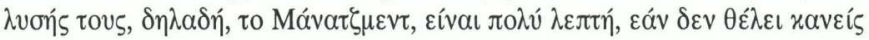




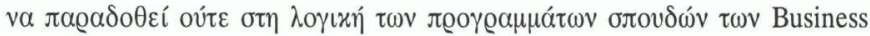

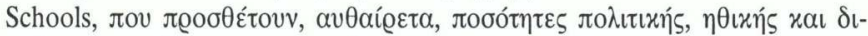

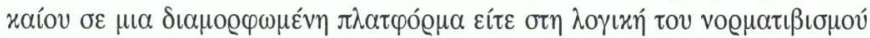

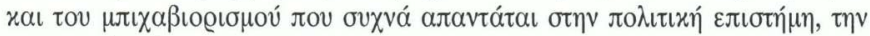

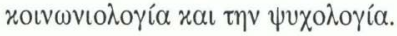

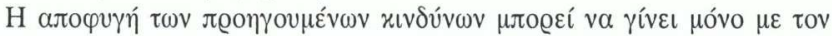

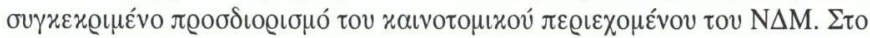

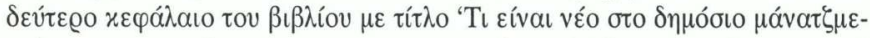

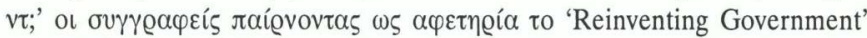

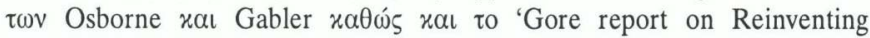

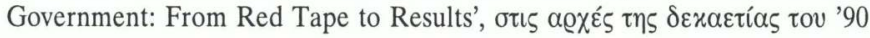

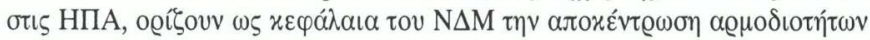

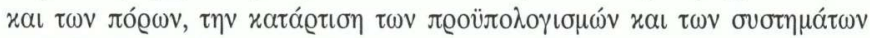

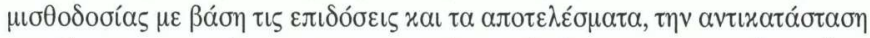

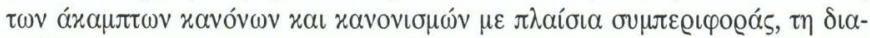

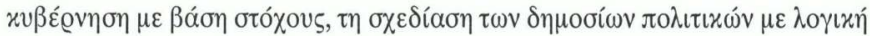

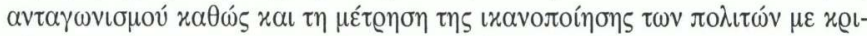

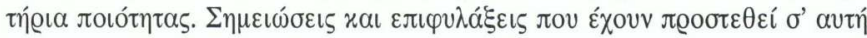

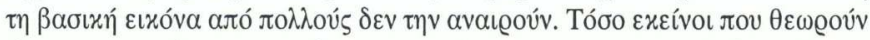

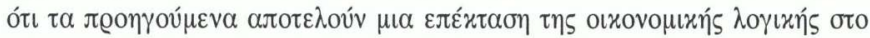

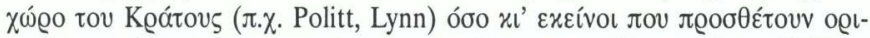

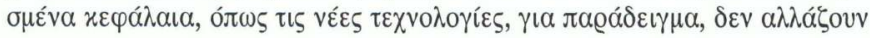

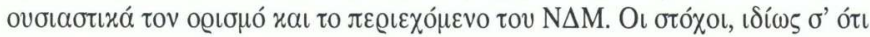

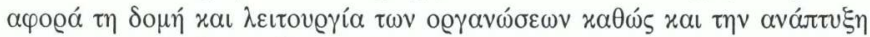

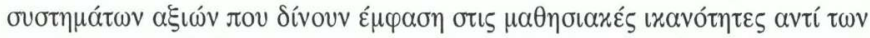

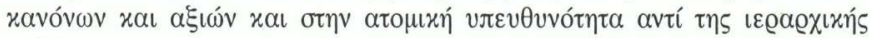

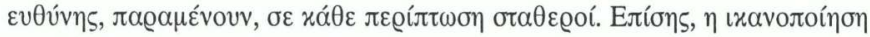

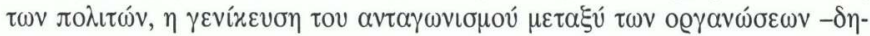

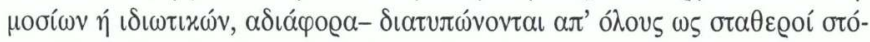

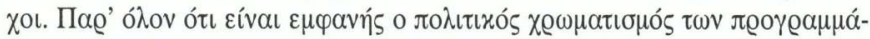

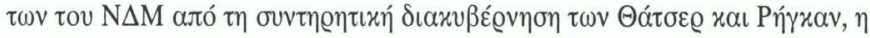

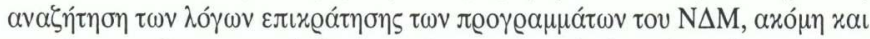

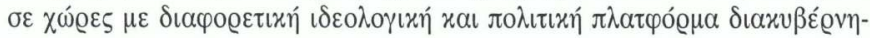

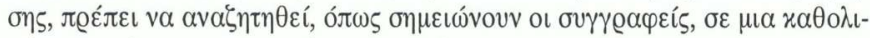

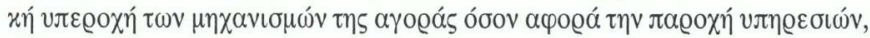

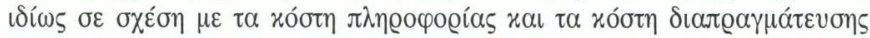

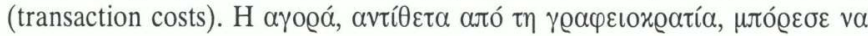




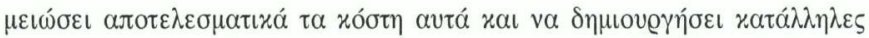

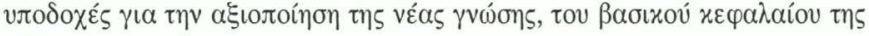

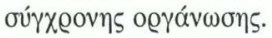

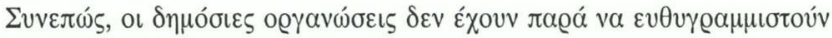

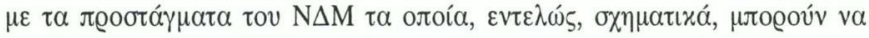

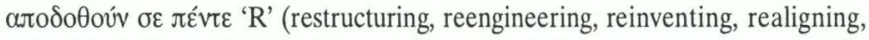

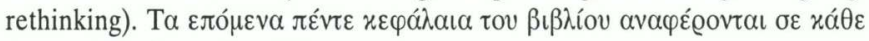

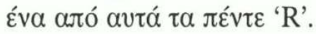

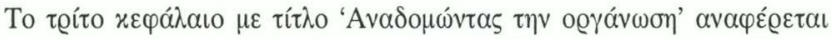

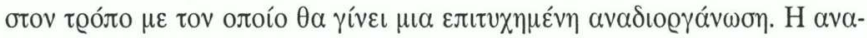

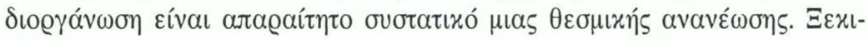

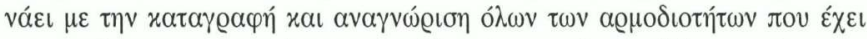

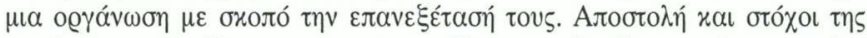

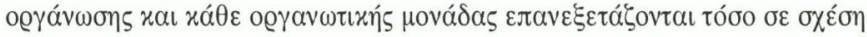

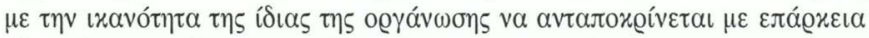

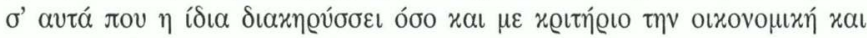

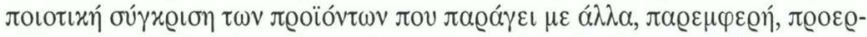

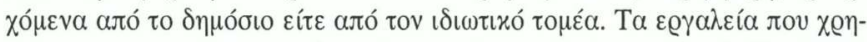

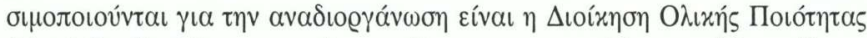

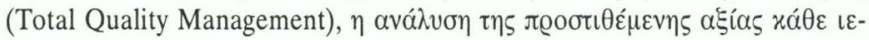

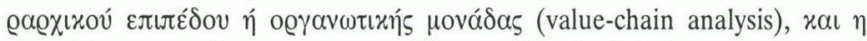

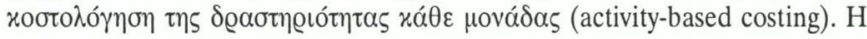

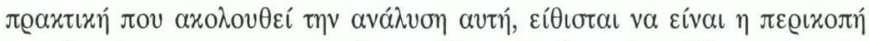

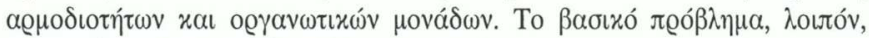

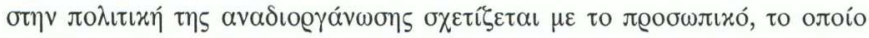

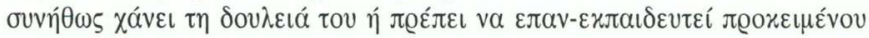

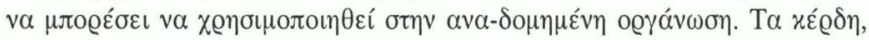

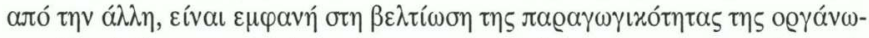

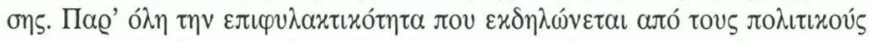

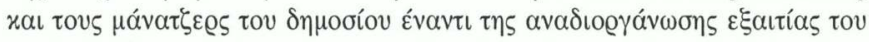

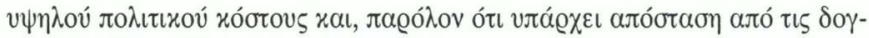

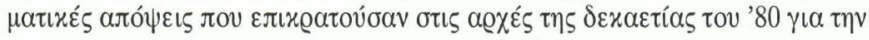

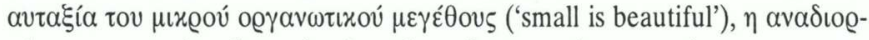

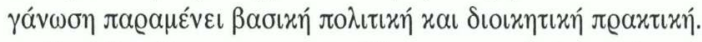

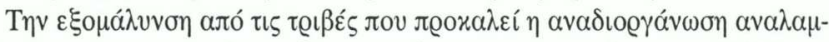

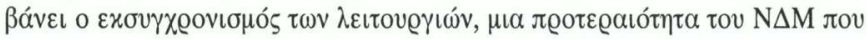

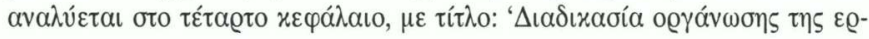




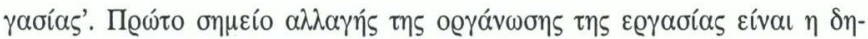

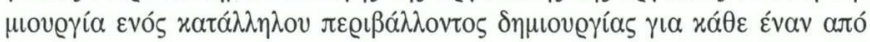

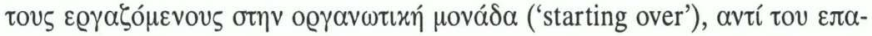

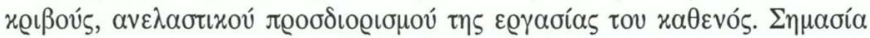

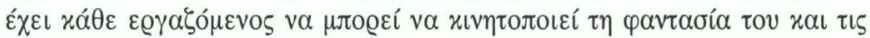

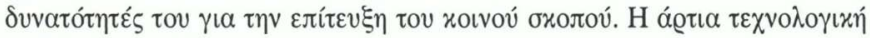

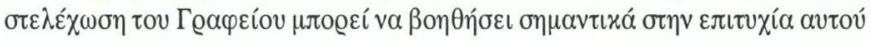

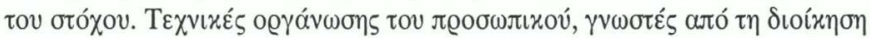

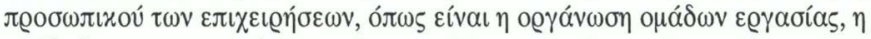

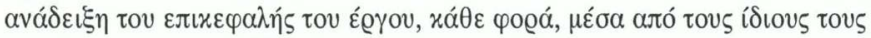

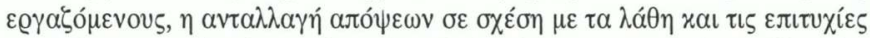

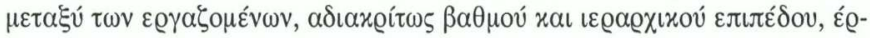

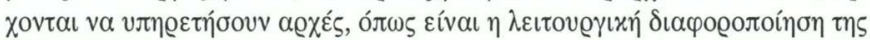

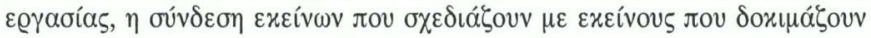

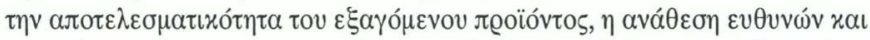

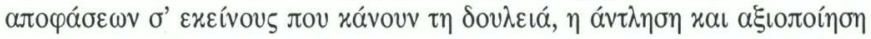

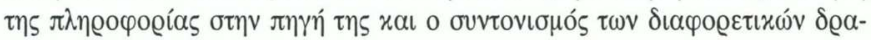

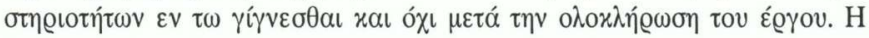
$\lambda \varepsilon เ \tau$

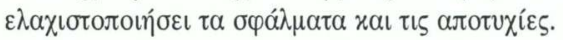

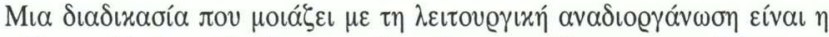

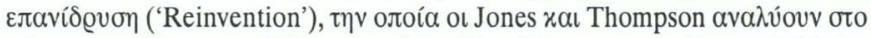

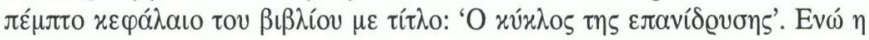

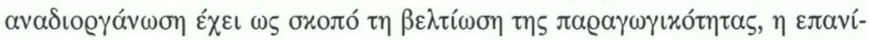

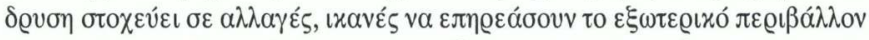

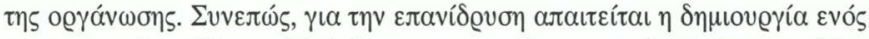

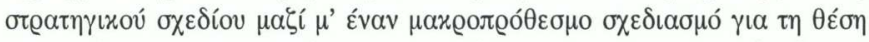

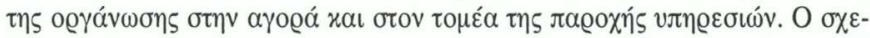

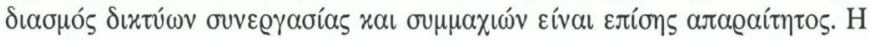

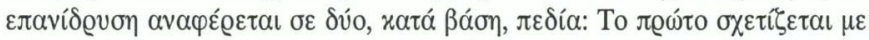

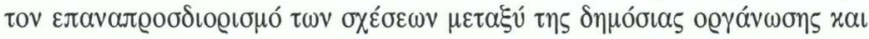

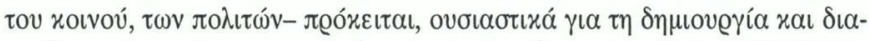

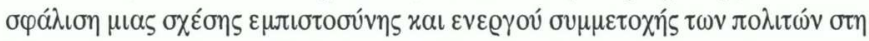

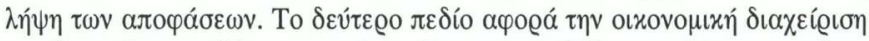

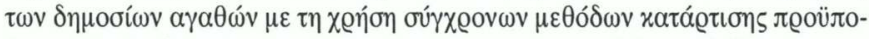

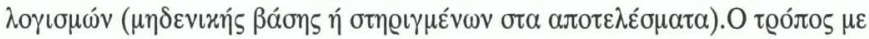

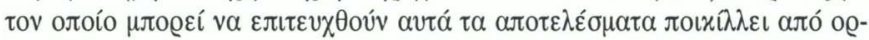




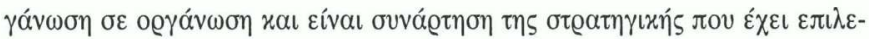

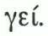

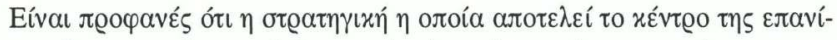

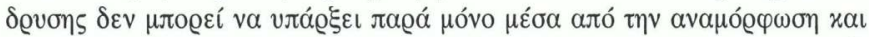

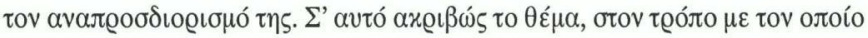

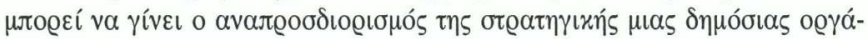

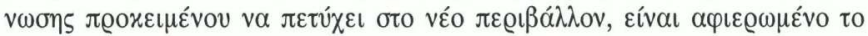

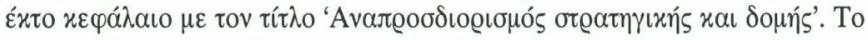

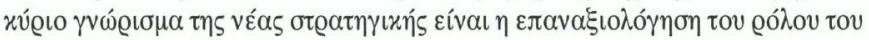

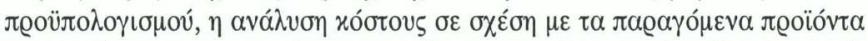

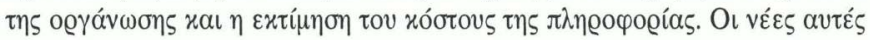

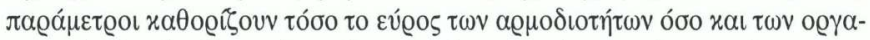

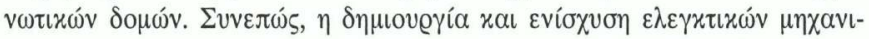

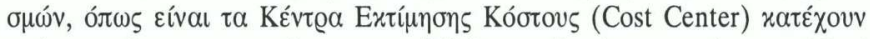

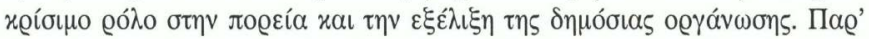

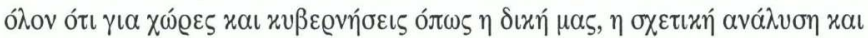

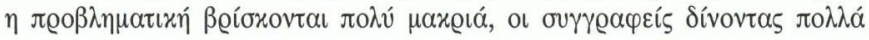

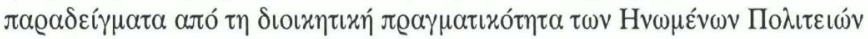

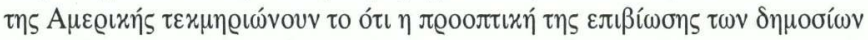

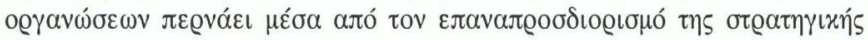
tous.

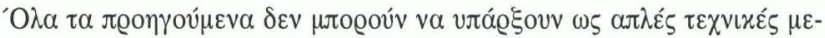

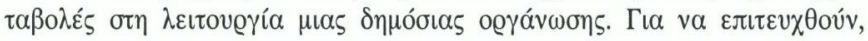

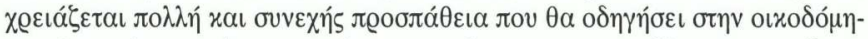

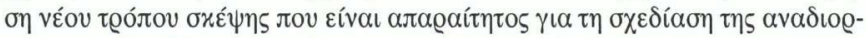

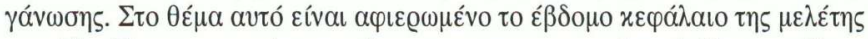

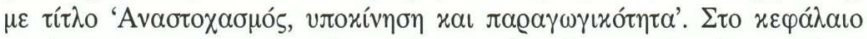

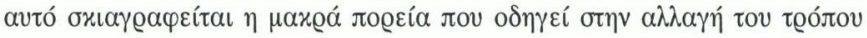

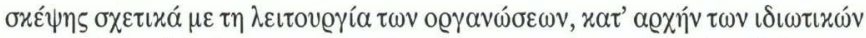

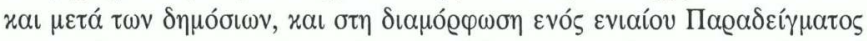

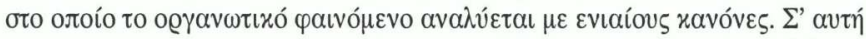

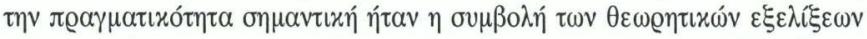

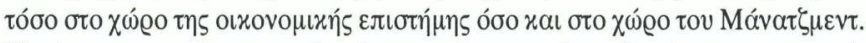

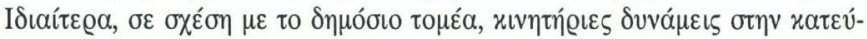

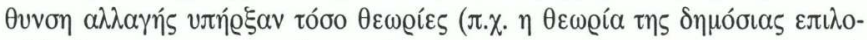

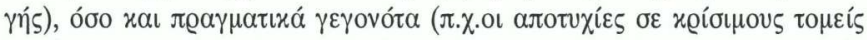

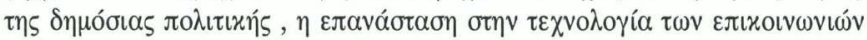




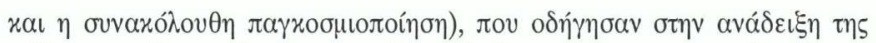

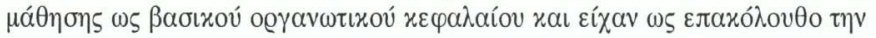

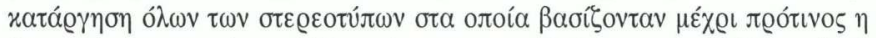

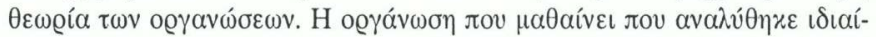

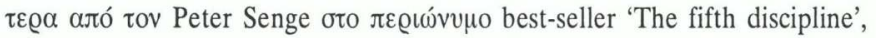

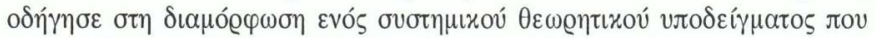

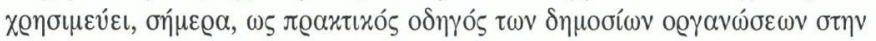

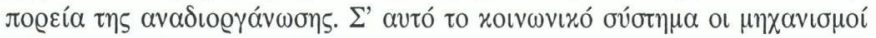

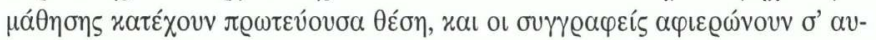

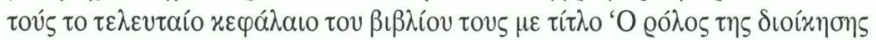

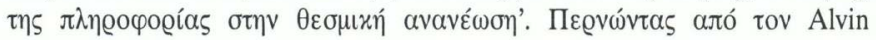

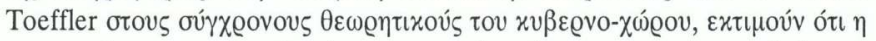

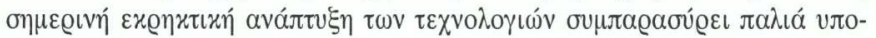

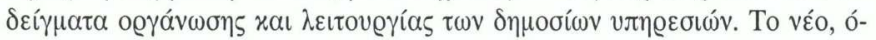

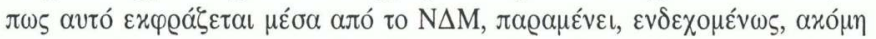

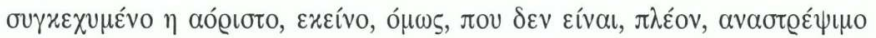

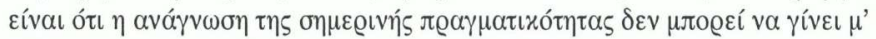

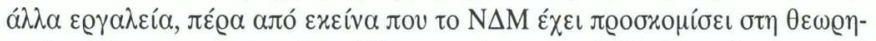

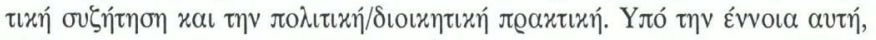

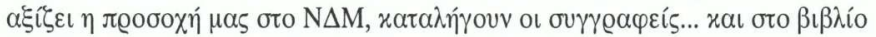
'Public Management: Institutional Renewal for the twenty-first century', тœo-

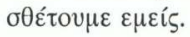

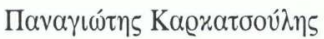

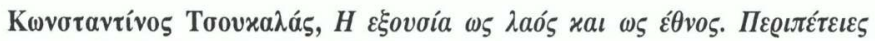

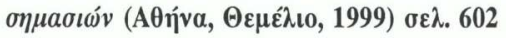

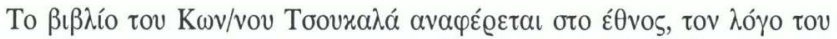

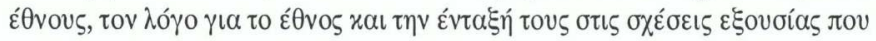

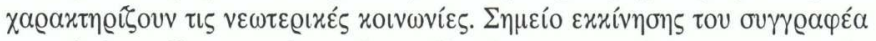

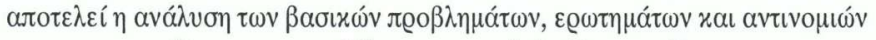

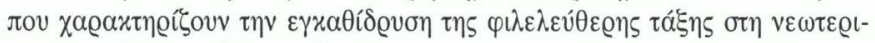

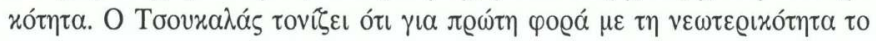

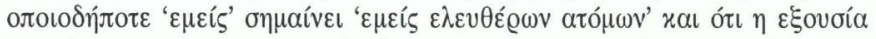

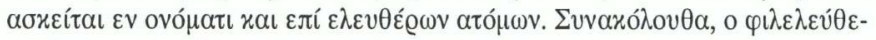

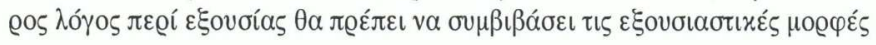

